\title{
Archéopages
}

Archéopages

Archéologie et société

46 | 2018

Maisons

\section{Habitats et territoires, occupations médiévales, Aisne-Oise}

\section{Louis Hugonnier et Denis Maréchal}

\section{OpenEdition}

1 Journals

Édition électronique

URL : https://journals.openedition.org/archeopages/4649

DOI : 10.4000/archeopages.4649

ISSN : 2269-9872

\section{Éditeur}

INRAP - Institut national de recherches archéologiques préventives

\section{Édition imprimée}

Date de publication : 1 décembre 2018

Pagination : 111-112

ISSN : 1622-8545

\section{Référence électronique}

Louis Hugonnier et Denis Maréchal, « Habitats et territoires, occupations médiévales, Aisne-Oise »,

Archéopages [En ligne], 46 | 2018, mis en ligne le 01 décembre 2020, consulté le 04 juin 2021. URL:

http://journals.openedition.org/archeopages/4649; DOI : https://doi.org/10.4000/archeopages.4649 


\section{4-2019 \\ Axe de recherche collectif 4420 \\ Inrap \\ Programmation 2010 \\ Axe général \\ de recherche 7 \\ Milieux ruraux et \\ urbains au Moyen Âge \\ et à l'époque moderne}

Habitats et territoires, occupations médiévales, Aisne-Oise.

\section{Louis Hugonnier}

Inrap, UMR 7058 «EDYSAN »

Denis Maréchal

Inrap

\begin{tabular}{lll}
\hline & Hélène Dulauroy-Lynch & Gaëtan Jouanin \\
Équipe & Service départemental & CRAVO, UMR 7209 \\
Germain Cuvillier & d'archéologie de I'Oise & "MNHN », \\
Service départemental & Caroline Font & archéozoologue \\
d'archéologie de l'Oise & Inrap, dessinatrice/ & Guillaume Lebrun \\
Martine Derbois & infographe, SIG & Service départemental \\
Inrap, céramologue & Richard Fronty & de l'Aisne, spécialiste \\
Gilles Desplanque & Inrap & des terres cuites \\
Service départemental & Marjorie Galois & architecturales \\
de l'Aisne & Inrap, céramologue &
\end{tabular}

Sylvain Rassat
CNRS, UMR 8596
"Centre Roland
Mousnier », topographe,
archéomaticien, création
de la base de données
Danaël Veyssier
Service départemental
d'archéologie de l'Oise
Sébastien Ziegler
Unité d'archéologie
de Château-Thierry

Institutions

Inrap

CNRS

Service départementa d'archéologie de l'Oise Service départemental de l'Aisne

Unité d'archéologie de Château-Thierry
Le principal objet d'étude (archéologique) de cet axe de recherche concerne les occupations médiévales sur les territoires actuels de l'Aisne et de l'Oise. Cette région, malgré son riche passé, était encore considérée récemment - lors du bilan régional portant sur la question des campagnes médiévales en Picardie en 2005 - comme le parent pauvre, au regard des voisins franciliens, normands ou champenois, en matière de dynamique, de synthèses et de recherches collectives (voire de participants « médiévistes ») et ce, malgré le potentiel évident des données picardes, région phare en archéologie préventive par les surfaces couvertes et le nombre des intervenants.

Trois objectifs majeurs ont été fixés en 2014: en premier lieu, celui de réunir les archéologues des différents services publics d'archéologie intervenant sur ces deux départements. Depuis, de nouveaux chercheurs (céramologue, archéozoologue, tuiliers...) nous ont rejoints. En deuxième lieu, il s'agissait de créer des bases de données interopérables (sites, structures, mobiliers, etc.), cartographiables (SIG), à entrées multiples (archéologiques, paléoenvironnementales, paléographiques...), utilisables à court terme pour la gestion du corpus d'étude, et consultables à moyen et long terme pour la communauté scientifique régionale. En troisième lieu, enfin, l'objectif était de traiter le corpus des opérations préventives de la thématique, entre les années 2005 et 2015, tout en gardant la porte ouverte aux opérations post-2015. Actuellement, chacun dispose du corpus en PDF de l'ensemble de ces opérations, gère ses travaux préparatoires de synthèses et rend compte de l'avancée de ses travaux en cours.

La majeure partie des objectifs fixés ont été réalisés avec la création des bases de données et l'utilisation de celles-ci, l'établissement et l'intégration des données du corpus 2005-2015, la mise en œuvre de tests cartographiques positifs, la publication des premiers travaux et la participation de membres de l'axe à deux colloques et à un séminaire liés à la thématique. La contrainte majeure reste les disponibilités des membres dans le cadre de leurs activités.

Pour les recherches à venir, l'accent est mis sur les travaux cartographiques (C. Font). Parallèlement, les thèmes à traiter, choisis par les différentes protagonistes, vont donner lieu à l'élaboration de synthèses concernant : les structures de stockage (D. Maréchal), les formes de délimitation spatiale des habitats (R. Fronty), les fonds de cabanes (L. Hugonnier), les sépultures en contexte d'habitat (D. Veyssier), les structures sur poteaux et particulières (G. Desplanque), les structures à combustion (G. Cuvillier), la céramique du haut Moyen Âge (M. Galois), les terres cuites architecturales (G. Lebrun), la place du haut Moyen Âge en contexte urbain (H. Dulauroy-Lynch, S. Ziegler), un état des lieux critique des archives anciennes exploitables (L. Hugonnier) ainsi qu'une approche des corpus archéozoologiques (G. Jouanin). Une fois ces études achevées, discutées collégialement, l'objectif sera d'en publier (rapidement) les résultats afin d'en assurer la communication à la communauté scientifique, régionale dans un premier temps. Cette étape fondamentale pourra alors susciter l'intérêt d'autres chercheurs régionaux non encore impliqués dans cette problématique de recherche.

À court terme, il est évident qu'il faut continuer sur cette dynamique, s'accorder sur les modalités d'intégration des anciennes données (avant 2005) et pérenniser la base de données pour les 
intégrations futures. Les discussions portent également sur la création de fiches par site, ce qui semble pertinent à ce stade. Elles seront aussi l'occasion de revenir sur l'aire géographique et chronologique prise en compte et d'élargir peutêtre les axes thématiques.

\section{Publications}

Hugonnier L., MaréChal D., avec la collaboration de Font C., à paraître, " Sources anciennes, planimétriques et archéologiques au service du temps long villageois : les cas de Chevrières et Couloisy (Oise) ", in Catafau A., Pasarius O. (dir.), Archéologie au village, Le village et ses transformations du Moyen Âge au premier cadastre, Actes du colloque tenu du 20 au 22 septembre 2017 à Perpignan, Archéologie du Midi Médiéval.

HugonNier L., MARÉCHAL D., 2016, « Le village comme objet d'étude : aperçu des travaux menés par l'ARC 4420 Habitats et territoires, occupations médiévales, Aisne-Oise », in "Évaluer le village », Séminaire coordonné par Jean-Philippe Chimier, Nicolas Fouillet et Stéphane Joly, UMR 7324 Citeres-LAT, Tours, 28 et 29 janvier 2016. http://www.centrerolandmousnier.fr/wp-content/ uploads/2015/og/TOURS-2016-pour-Roland-Mousnier.pdf
Hugonnier L., Rassat S., 2016, « Présentation des bases de données de l'ARC 4420 », in « Évaluer le village », Séminaire coordonné par Jean-Philippe Chimier, Nicolas Fouillet et Stéphane Joly, UMR 7324 Citeres-LAT, Tours, 28 et 29 janvier 2016. http://www. centrerolandmousnier.fr/wp-content/uploads/2015/og/TOURS2016-pour-Roland-Mousnier.pdf

Hugonnier L., Cuvillier G., Desplanque G., Font C., Maréchal D., Rassat S., VeysSier D., Ziegler S., avec la collaboration de Dulauroy-Lynch H., Galois M., à paraitre, « Habitats alto-médiévaux en Picardie. Premiers bilans (2005-2014) sur les territoires de l'Aisne et de l'Oise », in Actes du colloque de l'Association française d'archéologie mérovingienne, MontpellierLattes, 2015, supplément n 9, Archéologie du Midi Médiéval.

Hugonnier L., Arbault S., Derbois M., Desplanque G., Fronty R MarÉCHAL D., Rassat S., Ziegler S., 2014, «État de la recherche sur le "fait villageois" en Picardie méridionale. Nouvelles données et nouvelles perspectives ", Archéopages, $\mathrm{n}^{\circ}$ 40, Villages, p. 56-63. https://journals.openedition.org/archeopages/599
2013-2019

Projet collectif de recherche (PCR)

\section{Blois : ville et territoire ligérien depuis les premières installations humaines jusqu'à nos jours.}

\section{Viviane Aubourg \\ Ministère de la Culture, UMR 7324 « Citeres »}

Didier Josset

Inrap, UMR 7324 « Citeres »

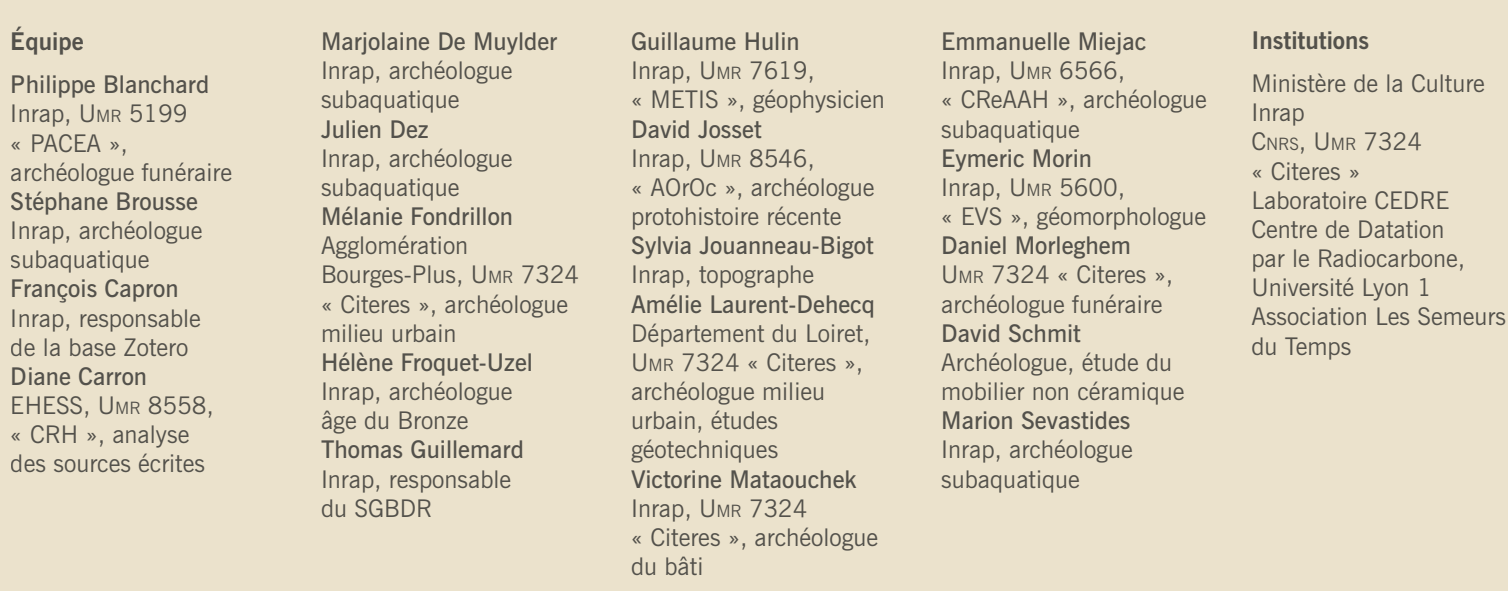

Depuis 2013, une vingtaine de chercheurs d'institutions diverses étudient l'histoire de l'espace urbanisé de Blois (Loir-et-Cher). Les recherches $\mathrm{du}$ PCR s'inscrivent dans le cadre des programmes nationaux définis par la Commission Territoriale de la Recherche Archéologique (axe 9) et dans les défis 6 (orientation 22) et 8 (orientation 30) de la Stratégie Nationale de Recherche. L'objectif principal concerne l'étude de la ville sur la longue durée et la production d'un document de synthèse qui répondra aux critères des documents d'évaluation du patrimoine archéologique des villes de France (Depavf) tout en intégrant les développements numériques et conceptuels proposés par les Synthèses Archéologiques Urbaines.

Pour la réalisation du Depavf, des outils spécifiques - base bibliographique Zotero, base de données spatialisées et Sig - ont été élaborés. L'interopérabilité du Sig avec PatriArche est garantie. La création et la spatialisation des composantes urbaines sont en cours. Les dépouillements de la documentation historique et des rapports de fouille se poursuivent. Ils permettent la constitution et l'ordonnancement d'un corpus considérable de données avec le développement de l'archéologie préventive.

Dans le but de consolider les synthèses historiques, un important volet du projet consiste à combler les lacunes documentaires dans trois domaines : l'espace urbanisé de la rive gauche - quartier Vienne, le lit mineur avec les aménagements fluviaux s'y trouvant et toute l'étendue du lit majeur, c'est-à-dire le Val de Blois. Ces thématiques ont été enrichies depuis 2013 par de nouvelles recherches en archives et des 